\title{
Guest Editors' Notes
}

\section{Beyond Bits and Bytes: The organizational dimension of digital preservation}

The problem with digital preservation is often reduced to its technical aspects: we seek solutions to storage and bitstream preservation, format migration or building emulation environments. In turn, organizational aspects of preservation are often dealt with almost as an afterthought (see Kenney and McGovern, 2003). However, for digital preservation to be sustainable, technical solutions have to be embedded in an organizational framework complementing and supporting the technological side. Linked closely with the notion of "institutional readiness", the organizational dimension of digital preservation comprises "the policies, procedures, practices, people" to support digital preservation (Cornell University Library and ICPSR, n.d.). These were the topics addressed in the session "Beyond bits and bytes: the organizational dimension of digital preservation" at the IASSIST 2013 conference in Cologne, on which this issue of the IASSIST Quarterly is based.

Looking back onto the last ten years of "digital preservation developments" in 2007, McGovern sees considerable progress in what she calls the "organizational leg" of digital preservation (no pag.). At the same time she identifies two particularly pressing issues: "the need to integrate the organizational policies for digital preservation into technological implementations and the need to develop and evolve digital preservation skills" (ibid.). It seems safe to assert that awareness of the importance of the organizational dimension has further increased since McGovern's assessment in 2007 , and that further progress has been made in addressing the practical issues arising in this dimension. This is, for example, a result of the increasing commitment of archives and repositories to audit and certification procedures - thus, all the standards in the European Framework for Audit and Certification of Digital Repositories require archives to address the organizational dimension along with the technological.

But despite the progress already made the articles in this issue attest to the fact that a number of challenges still face digital preservation (and individual institutions accordingly) in the organizational dimension. Expanding on the questions of change management, professional development and education, the creation of policies, and certification, the authors draw our attention to issues which we need to continue to address to further strengthen the organizational dimension and its connection to the other legs of the "three-legged stool for digital preservation" (McGovern, 2007, no pag.): technology and (human, financial) resources.
In her paper "Time to change - effects and implications of digital preservation in an organizational context" Michelle Lindlar from the German National Library of Science and Technology (TIB) presents a systematic overview of the prerequisites an institution has to fulfill when introducing digital preservation activities, and of the (organizational) changes this entails. Identifying two "layers of change" (initial, and ongoing), Lindlar carries out analyses of three areas requiring effective change management: preservation strategy, staff, and system choice. She shows which initial changes the introduction of digital preservation will effect in these areas and which ongoing efforts an organization has to make to keep its preservation activities up to par. To support this objective, the author recommends the implementation of an "organizational watch" in addition to a technology and community watch.

The next paper, "Digital curation training - the nestor activities" by Stefan Strathmann from the Göttingen State and University Library and Achim Oßwald from Cologne University of Applied Sciences addresses the issue of professional training and education in digital preservation. The authors describe the efforts made by a working group focusing on qualification issues set up as part of the nestor competence network. To improve education in this field in German-speaking countries, a qualification program has been developed and implemented during the last decade. The article introduces the approach taken to digital preservation training, which is based on e-learning tutorials, schools, seminars, and publications, and sketches future plans of the working group.

In "How to develop a preservation policy? Guidelines from the nestor working group,"'Yvonne Friese from the Leibniz Information Centre for Economics introduces another activity from the context of the nestor network. Taking its cue from the observation that a gap exists between the number of institutions involved in digital preservation activities and those who have published a preservation policy, the nestor working group started with the creation of guidelines to help institutions to develop their own preservation policy. By supporting institutions to create a policy tailored to their individual scope and mandate, the guidelines, which will be published in early 2014, can help to close the observed gap and thus support the establishment of more sustainable and reliable preservation services.

In the last paper of this issue, "Tried and trusted: Experiences with certification processes at the GESIS Data Archive", Natascha Schumann from the GESIS Leibniz Institute for the Social Sciences investigates the organizational impact that a certification process can have on an established 
archive. After giving an overview of existing approaches to certification and audit for trusted digital repositories she discusses the GESIS Data Archive's experiences with the Data Seal of Approval and the benefits reaped from preparing the certification process

Dr. Astrid Recker, Natascha Schumann

January 2014

Guest Editors

\section{References}

Cornell University Library and ICPSR (n.d.). Where to Begin? An organization's digital preservation program. In: Digital Preservation Management: Implementing short-term strategies for long-term problems. [online tutorial] Available at <http://www.dpworkshop.org/dpm-eng/conclusion. html $>$ [Accessed 8 January 2014]

Kenney, A.R. and McGovern, N.Y., 2003. The Five Organizational Stages of Digital Preservation. In: Scholarly Publishing Office (University of Michigan), ed. Digital Libraries: A Vision for the 21st Century: A Festschrift in Honor of Wendy Lougee on the Occasion of her Departure from the University of Michigan. [online] Ann Arbor: University of Michigan Library. no pag. Available at: <http://hdl.handle. net/2027/spo.bbv9812.0001.001> [Accessed 8 January 2014]

McGovern, N.Y., 2007. A Digital Decade: Where Have We Been and Where Are We Going in Digital Preservation? [online] In: RLG DigiNews, 11(1). Available at: <http:// deepblue.lib.umich.edu/bitstream/handle/2027.42/60441/ McGovern-Digital_Decade.html;jsessionid=1789D2837E80E OB5F0A4F588CC4DDEA2> [Accessed 8 January 2014] 